\title{
High Photocatalytic Performance of Modified Bismuth Oxychloride Semiconductor under Sunlight
}

\author{
PREEJA. P. THATTIL and A. LEEMA ROSE* \\ Department of Chemistry, Holy Cross College (Autonomous), Affiliated to Bharathidasan University, \\ Tiruchirappalli-620 002, Tamil Nadu, India. \\ *Corresponding author E-mail: leemarose25@gmail.com \\ http://dx.doi.org/10.13005/ojc/370402
}

(Received: July 08, 2021; Accepted: August 09, 2021)

\begin{abstract}
In recent years, the bismuth compounds have gained much interest due to their potential applications in the field of Photocatalysis. In our present work, Bismuth oxychloride Photocatalyst and Aluminium fluoride doped Bismuth oxychloride photocatalyst were synthesized by simple chemical methods using bismuth nitrate pentahydrate as the precursor. The synthesized photocatalysts were characterized by different analytical techniques such as X-ray diffraction analyses, Ultraviolet-Diffuse reflectance spectrum, Field Emission-Scanning Electron Microscopy, Energy dispersive X-ray analyses, Fourier transform infrared spectroscopy studies and BET surface area analysis. The photocatalytic performances of the as-synthesized doped and undoped bismuth oxychloride photocatalyst were tested towards the degradation of Acid green 1 dye. The parameters such as the effect of $\mathrm{pH}$, catalyst concentration and initial dye concentration are optimized, and the kinetic studies are carried out for the photocatalytic dye degradation process. The experimental results showed that about $80 \%$ of the Acid green 1 dye got decolourized within 90 min by effective air purging under natural sunlight radiation in the presence of the AIF-BiOCl photocatalyst under optimized conditions.
\end{abstract}

Keywords: AlF-BiOCl photocatalyst, XRD, HR-SEM, Acid green 1 dye, Air Oxidation, Solar radiation.

\section{INTRODUCTION}

Water pollution has become a major environmental concern as it encourages the transmission of many waterborne diseases, especially in developing nations. The paper, textile, leather, printing and dyeing industries which utilize a large amount of coloring materials such as dyes that are non-biodegradable and synthetically stable poisons are released into the nearby water bodies. This release of the effluent into the nearby water streams are considered to be a serious environmental hazard to both aquatic as well as human life ${ }^{1}$. Different water treatment techniques such as Coagulation, flocculation, adsorption, membrane separation, UV/Ozone treatment have been employed for the removal of the organic pollutants from the wastewater ${ }^{2-5}$. Among the various water treatment technologies, the development of advanced oxidation process in the past years have gained considerable interest by the researchers due to

This is an Open Access article licensed under a Creative Commons license: Attribution 4.0 International (CC- BY). Published by Oriental Scientific Publishing Company @ 2018 
the low-cost, eco-friendliness and the potential to completely degrade the organic pollutants into harmless products such as carbon dioxide and water ${ }^{6-10}$. Among many semi-conductor nanocatalysts bismuth-based semiconductors have gained tremendous consideration in the field of photocatalysis for its remarkable action against hazardous pollutants ${ }^{11-13}$. Bismuth oxychloride is reported to show excellent photocatalytic activity in the degradation of variety of organic pollutants such as dyes, pesticides, phenols and microbes as it possesses a high chemical stability ${ }^{14}$. Many researchers have reported the excellent photocatalytic activity of Bismuth oxychloride photocatalyst which is attributed to the layered structure of $\left[\mathrm{Bi}_{2} \mathrm{O}_{2}\right]^{2+}$ monolayer and dual ' $\mathrm{Cl}$ ' layers ${ }^{15}$. However, its large band gap (3.17-3.54 $\mathrm{eV}$ ) energy values have limited its activity as a photocatalyst towards many pollutants ${ }^{16}$. Hence, in order to overcome these limitations many modifications of bismuth oxychloride photocatalyst have been researched by the materials scientists in the recent years. Among which coupling and doping of the $\mathrm{BiOCl}$ photocatalyst with other suitable semiconductors are found to be effective in getting better photo-response and also facilitate the separation of photo induced electron-hole pairs which interact with the hydroxyl radicals to provide excellent photodegradation of the contaminants ${ }^{17}$. Hence, in our present work we have mainly focused on synthesizing a modified bismuth oxychloride photocatalyst via a facile low cost approach using water as the solvent, bismuth nitrate pentahydrate as the precursor, potassium chloride as the source of halogen and Aluminium fluoride as the dopant. The as-synthesized bismuth oxychloride photocatalyst have been employed for the degradation of the textile dye Acid green 1. It is a nitroso dye with the molecular formula $\left(\mathrm{C}_{30} \mathrm{H}_{15} \mathrm{FeN}_{3} \mathrm{Na}_{3} \mathrm{O}_{15} \mathrm{~S}_{3}\right)$ and Molecular Weight (878.46). The dye shows excellent absorption and excellent light fastness. It is mainly used in solar salt industry and wool, silk and nylon fabric dyeing and printing can also be used for leather dyeing ${ }^{18,19}$. The chemical structure and UV-Visible absorption spectrum of the Acid green 1 dye is shown in Figure 1.

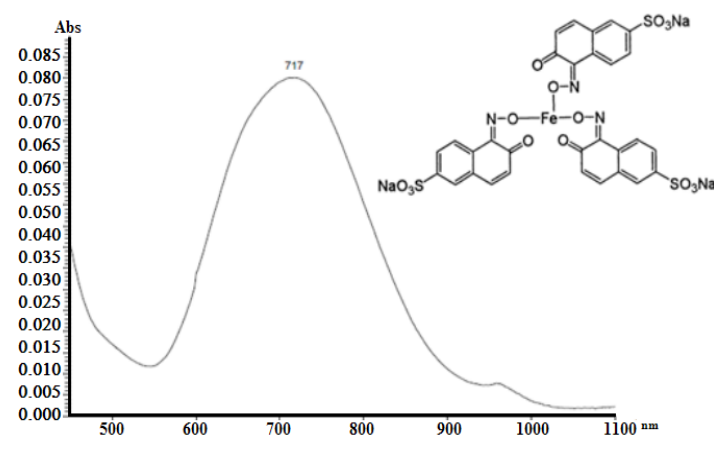

Fig.1. Shows the UV-Visible spectrum and Chemical structure of Acid green 1 dye

EXPERIMENTAL

\section{Materials}

All materials used in this experiment are of analytical grade. Bismuth nitrate pentahydrate (M.W. 485.07, purity $98 \%$ ) and Acid green 1 dye was purchased from S. D. Fine Chemicals., Potassium chloride from Merck and ethanol (99.9\%) was purchased from Changshu Hongsheng Fine Chemical Co. Ltd. The solution $\mathrm{pH}$ was measured using Elico digital $\mathrm{pH}$ meter. The decolourization of dyes was monitored by UV-Visible spectrophotometer (Hitachi-U2910).

\section{Synthesis of AIF-BiOCI Photocatalyst}

Bismuth nitrate pentahydrate is used as a precursor to prepare the bismuth oxychloride catalyst. In a typical synthesis, $0.1 \mathrm{M}$ bismuth nitrate pentahydrate is dissolved in $100 \mathrm{~mL}$ double distilled water. About $3 \mathrm{wt} \%$ of Aluminium fluoride salt is added to the precursor solution and it is continuously stirred for about half an hour and this solution is labeled as A. Potassium chloride is used as a source of chlorine which is dissolved in a minimum quantity of double distilled water labeled as solution $B$. The solution $B$ is added to $A$ and the mixture is stirred continuously for 30 minutes. The $\mathrm{pH}$ of the solution is adjusted to 2 using aqueous ammonia solution. The stirring is continued for $7 \mathrm{~h}$ and the obtained precipitate is repeatedly washed with double distilled water, dried in a hot air oven followed by calcinations process. 0.5, 1, 2 and $4 \mathrm{wt} \%$ of $\mathrm{AlF} / \mathrm{BiOCl}$ photocatalyst is prepared by adopting the same procedure and bare Bismuth oxychloride catalyst is prepared without the addition of Aluminium fluoride as the dopant. 


\section{Characterization}

The instrument UV-Spectrophotometer (Hitachi U2910) was used for measuring the decrease in absorbance of the dyes throughout the experiment for all the parameters optimized. The morphological characterizations of the synthesized $\mathrm{AlF} / \mathrm{BiOCl}$ and $\mathrm{BiOCl}$ photocatalyst were investigated by HR-SEM with EDAX (FEI Quanta FEG 200-High Resolution Scanning Electron Microscope). The crystallinity and crystal phase of the as-synthesized photocatalysts were analyzed by X-ray diffraction (XRD, Rigaku) patterns with Cu-ka Radiation $(\lambda=$ $1.54178 \AA$ ) in the range of $20-65$ degree is scanned at $40 \mathrm{kV}$. The UV-DRS are carried out with the help of the instruments UV-Spectrophotometer SHIMADZU/ UV-2600, BET surface area analysis using Quanta chrome instruments, Autosorb IQ series and Fourier transform infrared spectroscopy (Bruker Tensor-27) for the confirmation of the metal-oxide bond in the synthesized photomaterial.

\section{Photocatalytic Degradation Experiments}

About $1.13 \times 10^{-5} \mathrm{~mol} /$ Lof Acid green 1 dye was prepared as the stock solution, from which required volume was withdrawn for each experiment. All the photocatalytic experiments were carried out on sunny days between 11 am to $2 \mathrm{pm}$. The suspensions were magnetically stirred in the dark for $15 \mathrm{~min}$ to attain adsorption-desorption equilibrium between dye and the catalyst. Before exposing the dye solution to sunlight irradiation, the initial absorption peak was recorded. To evaluate the effect of initial dye concentration, the concentration of the dye varied from $1.13 \times 10^{-5} \mathrm{~mol} / \mathrm{L}$ to $5.69 \times 10^{-5} \mathrm{~mol} / \mathrm{L}$. The experiment was continued for $3 \mathrm{~h}$ at appropriate intervals small aliquots of the solution are withdrawn and the decrease in the absorbance is noted. The effect of $\mathrm{pH}$ was studied by adjusting the solution using $\mathrm{NaOH}$ and $\mathrm{HCl}$. The blank experiments were performed in the dark at room temperature following the above procedure. The percentage decolourization was calculated using the formula

$\frac{C 0-C}{C 0} \times 100$

Where $\mathrm{C}_{0}$ is the concentration of the dye solution at $\mathrm{t}=0$ and $\mathrm{C}$ is the concentration of the dye solution at time $t$.

\section{RESULTS AND DISCUSSION}

\section{X-Ray Diffraction Analysis}

The crystalline phase of the synthesized AlF-BiOCl and $\mathrm{BiOCl}$ photocatalyst is investigated by using powder X-ray diffraction analysis. The XRD pattern of the synthesized material is shown in Fig. $2 a$ and $2 b$. The sharp diffraction patterns observed for the synthesized AIF doped BiOCl and bare $\mathrm{BiOCl}$ photocatalyst suggests that these photocatalysts are highly crystalline in nature. The diffraction peaks at $2 \theta$ positions $12.1,24.2,26,32.5$, 33.6, 36.7, 41, 46.7, 49.8, 55.2, 58.7, 68.2, 75.1, 77.6 corresponds to the crystal planes (001) (002) (101) (101) (102) (003) (112) (200) (004) (104) (212) (114) (220) (214) and (006) respectively, according to JCPDS card No. 85-0861. As no additional diffraction peaks are observed in the doped $\mathrm{BiOCl}$ photocatalyst or no other peaks are observed which might arise from impurity, it is concluded that the synthesized Bismuth oxychloride photocatalyst samples are pure. In the XRD pattern, the peak (102) is found with maximum intensity indicating it to be the preferred growth plane ${ }^{20}$.

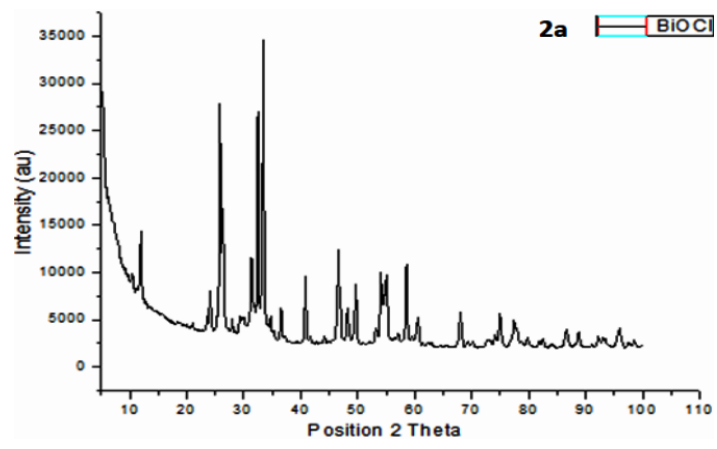

Fig. 2a. Shows the XRD pattern of the Synthesized Bismuth oxychloride photocatalyst

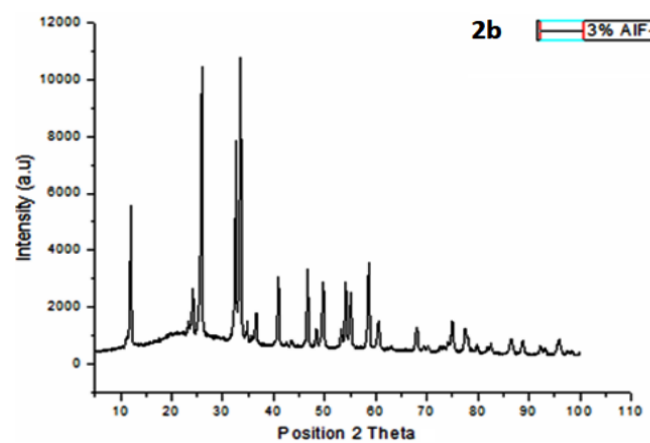

Fig. 2b. shows the XRD pattern of the synthesized AIF doped $\mathrm{BiOCl}$ photocatalyst 


\section{HR-SEM and EDAX Analysis}

The morphology of the $\mathrm{BiOCl}$ and AIF doped $\mathrm{BiOCl}$ photocatalysts are studied from the scanning electron microscopic technique. It is found from the SEM micrographs that the synthesized Bismuth oxychloride photocatalyst possess nanoflake like structure and the width of the nanoflakes ranges from 69.3 to $75.1 \mathrm{~nm}$ and the AIF-BiOCl photocatalyst also possessed flake-like arrangement which is shown in the SEM images Fig. 3a and 3b. Energy dispersive $\mathrm{X}$-ray analysis is used to determine the major elemental composition in the synthesized materials ${ }^{21}$. Using this technique, the elemental composition of the synthesized materials is obtained with high resolution. The EDAX analysis data confirmed that the elements Bismuth, oxygen and chlorine are present in major composition without any other impurity in the $\mathrm{BiOCl}$ photocatalyst and the presence of aluminium, fluorine, Bismuth, oxygen and chlorine in the synthesized AIF-BiOCl photocatalyst is also confirmed from the EDAX data shown in Figure $4 \mathrm{a}$ and $4 \mathrm{~b}$.

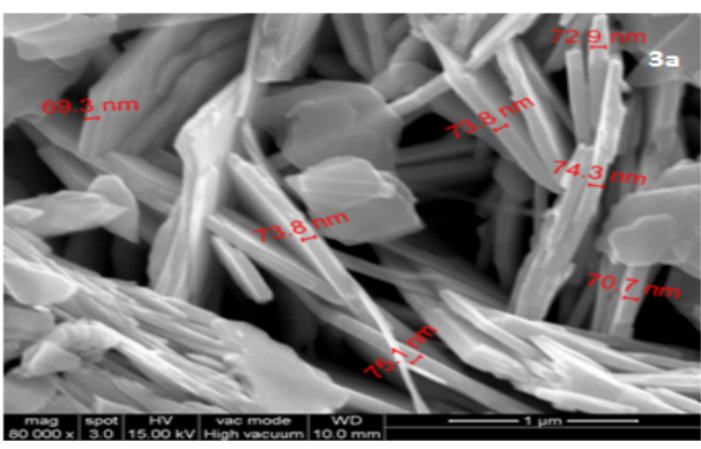

Fig. 3a. shows the FE-SEM images of the synthesized Bismuth oxychloride photocatalyst

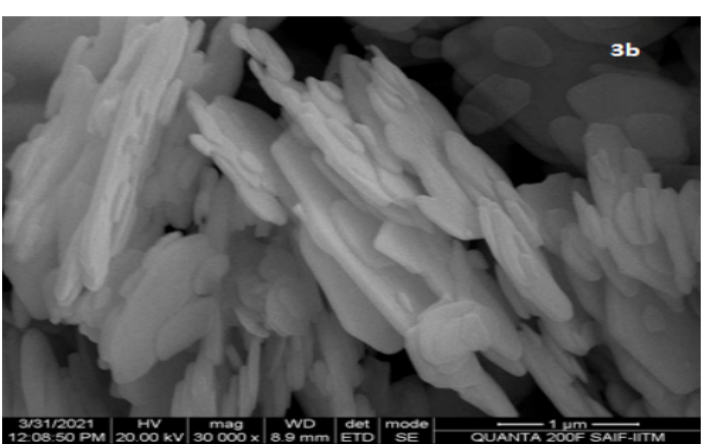

Fig. 3b. Shows the FE-SEM images of the synthesized AIF-BiOCI photocatalyst

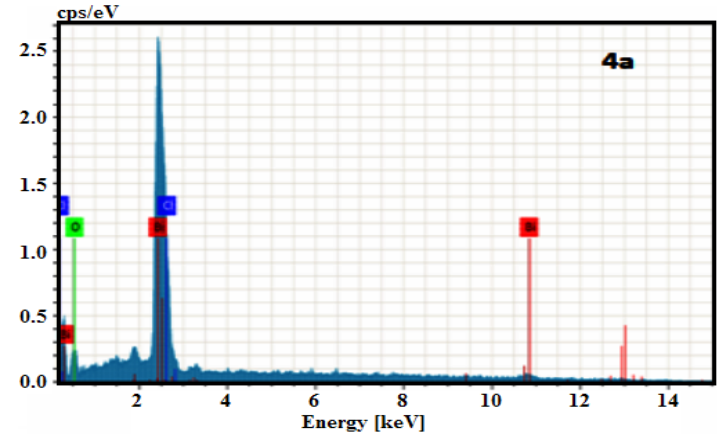

Fig. 4a. Shows the EDAX images of the synthesized Bismuth oxychloride photocatalyst

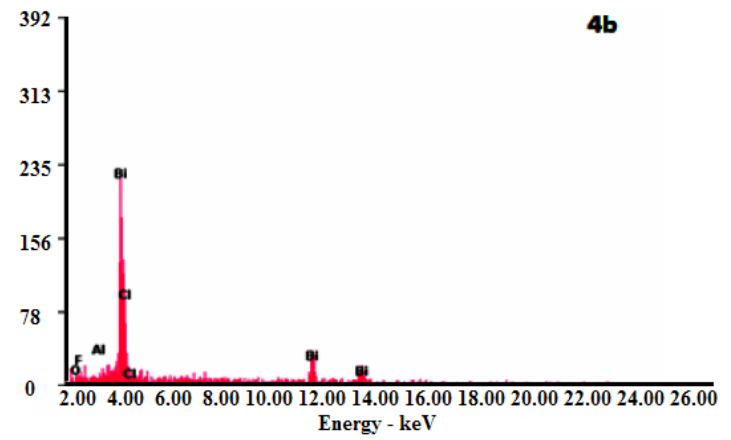

Fig. 4b. Shows the EDAX images of the synthesized AIF-BiOCI photocatalyst

\section{UV-Diffuse reflectance spectrum}

The band gap measurements of the synthesized bismuth oxychloride and aluminium fluoride doped bismuth oxychloride photocatalyst is done with the help of UV-Visible diffuse reflectance spectroscopy which paves way to understand whether there are changes in the band gap of the modified semiconducting photomaterial and whether the photomaterial absorbs the UV or Visible radiation ${ }^{22}$. The band gap of the synthesized AIF-BiOCl and bare $\mathrm{BiOCl}$ photocatalyst is calculated using the following relation: $E_{q}=1240 / \lambda$, where $\lambda$ is the cut off wavelength and $E_{g}$ is the band gap energy in electron volts $(e V)$. The band gap energy of the bismuth oxychloride photocatalyst is found to be $3.2 \mathrm{ev}$ and the band gap value of the Aluminium fluoride doped bismuth oxychloride photocatalyst is calculated to be $2.86 \mathrm{ev}$.

\section{Fourier Transform Infra-Red spectroscopy}

The metal-oxygen bond formation in the synthesized $\mathrm{AIF}-\mathrm{BiOCl}$ and bare $\mathrm{BiOCl}$ photocatalyst is confirmed from the fourier transform infra-red spectroscopy shown in Fig. 6. The band observed at $3435 \mathrm{~cm}^{-1}$ in both AlF-BiOCl and bare $\mathrm{BiOCl}$ photocatalyst corresponds to the stretching vibrations of hydroxyl group. The peak at $1630 \mathrm{~cm}^{-1}$ confirms 
the bending vibrations of the water molecules which are adsorbed on the surface of the photocatalyst. The broad bands between 412 and $850 \mathrm{~cm}^{-1}$ are due to the framework vibrations of $\mathrm{Bi}-\mathrm{O}$ bonds. The peak at about $532 \mathrm{~cm}^{-1}$ resulted from the symmetrical stretching vibration of the $\mathrm{Bi}-\mathrm{O}$ band is a typical peak of $\mathrm{BiOCl}$ photocatalyst which is observed in both AIF$\mathrm{BiOCl}$ and bare $\mathrm{BiOCl}$ photocatalysts ${ }^{23-25}$.

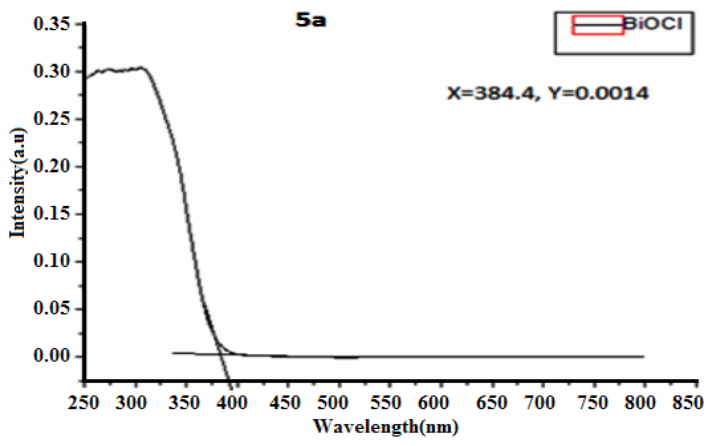

Fig. 5a. shows the UV-DRS plot of the synthesized Bismuth oxychloride photocatalysts

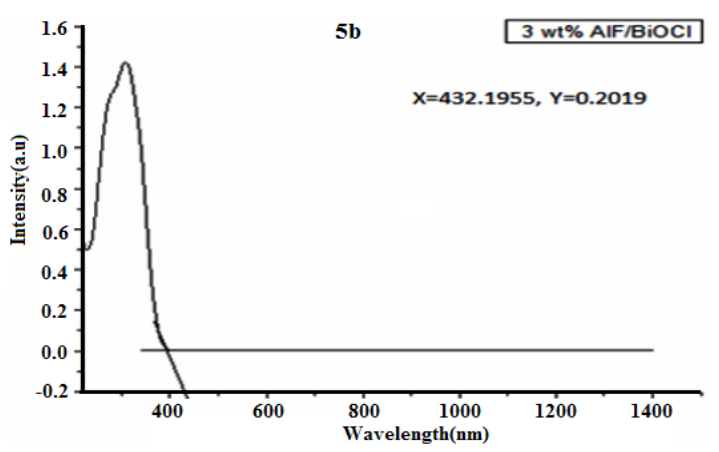

Fig. 5b. shows the UV-DRS plot of the synthesized Bismuth oxychloride and AIF-BiOCl photocatalysts

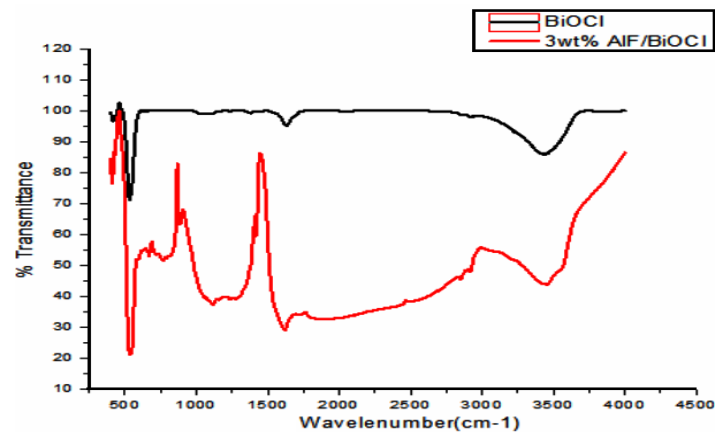

Fig. 6. Shows the FTIR spectrum of the synthesized $\mathrm{BiOCl}$ and $\mathrm{AIF-BiOCl}$ photocatalyst

\section{BET Surface area measurements}

Surface area is a crucial factor for determining the catalytic activity of the bare as well as surface modified photocatalysts ${ }^{26,27}$. The specific surface area as well as the BJH pore size distribution of $\mathrm{AlF}-\mathrm{BiOCl}$ and bare $\mathrm{BiOCl}$ photocatalysts are measured by Nitrogen adsorption-desorption isotherms and the plots are shown in Fig. 7a and 7b. The $\mathrm{N}_{2}$ adsorption-desorption plots for samples $\mathrm{BiOCl}$ and $\mathrm{AIF} / \mathrm{BiOCl}$ (3 wt\%) are categorized as type IV isotherms, which proves the existence of pores in between each inter-crossed linked nanoplates ${ }^{28,29}$. From the BET surface area measurements, it is found that the specific surface area of the bismuth oxychloride photocatalyst is $18.726 \mathrm{~m}^{2} / \mathrm{g}$ with a pore volume of $0.036 \mathrm{cc} / \mathrm{g}$ and the specific surface area of the AIF-Bismuth oxychloride photocatalyst is 14.837 $\mathrm{m}^{2} / \mathrm{g}$ with a pore volume of $0.030 \mathrm{cc} / \mathrm{g}$.

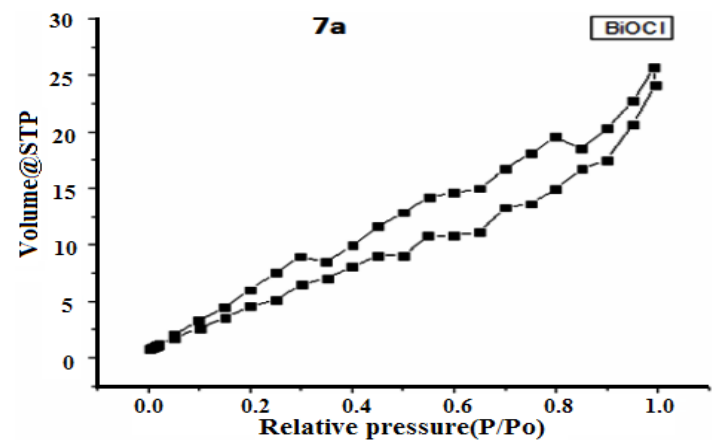

Fig. 7a. Shows the Nitrogen adsorption-desorption isotherms of the synthesized BiOCl photocatalyst

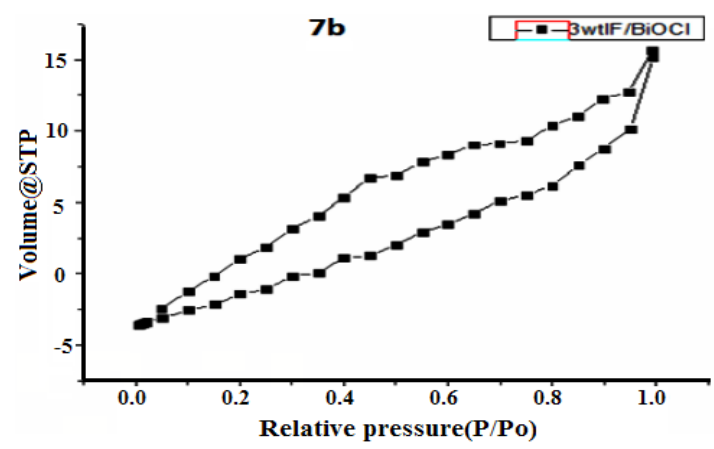

Fig. 7b. shows the Nitrogen adsorption-desorption isotherms of the synthesized AIF-BiOCI photocatalyst

Photocatalytic Degradation studies of Acid green 1 dye Effect of $\mathrm{pH}$

The influence of $\mathrm{pH}$ on the photocatalytic decolourization of acid green 1 dye $\left(1.13 \times 10^{-5} \mathrm{~mol} / \mathrm{L}\right)$ is studied by varying the $\mathrm{pH}$ range from 3 to 12 at a catalyst concentration of $15 \mathrm{mg}$ per $50 \mathrm{~mL}$ of the dye solution. The maximum decolourization efficiency is observed at $\mathrm{pH} 5$ which is shown in Fig. 8. The higher degradation of anionic acid green 1 dye at acidic $\mathrm{pH}=5$ is due to its interaction with the $\mathrm{H}^{+}$ions. 
On the other hand, in alkaline medium the negatively charged $\mathrm{BiOCl}$ catalyst and the anionic acid green 1 dye competes for interaction with hydroxyl ions thereby resulting in low photocatalytic degradation process ${ }^{30}$.

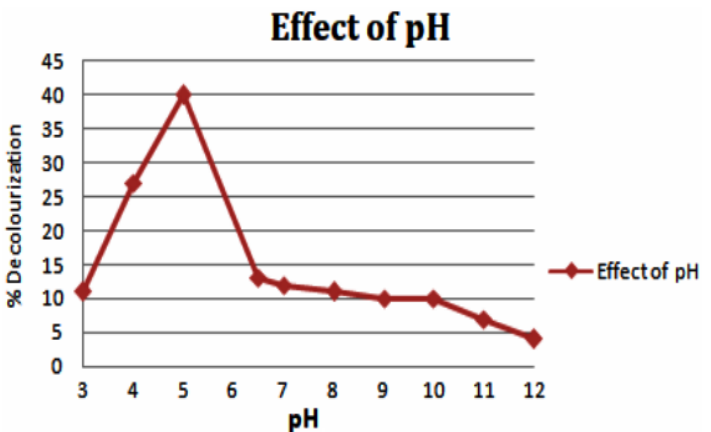

Fig. 8. $1.13 \times 10^{-5} \mathrm{~mol} / \mathrm{L}$ of acid green 1 dye solution, $25 \mathrm{mg}$ of $\mathrm{BiOCl}$ catalyst, $\mathrm{pH}$ varied from 3 to 12 , air flow rate $=2.5 \mathrm{~L} / \mathrm{min}$ under sunlight

\section{Effect of Catalyst Concentration}

For the effective decolourization of acid green 1 dye the bismuth oxychloride catalyst dosage is optimized by varying the catalyst concentration from $5 \mathrm{mg}$ to $55 \mathrm{mg}$ per $50 \mathrm{~mL}$ of the dye solution at optimized $\mathrm{pH}$ level 5 . The maximum decolourization is observed for $15 \mathrm{mg}$ of the catalyst dosage which is shown in Fig. 9. On increasing the $\mathrm{BiOCl}$ catalyst dosage a decrease in the photocatalytic dye decolourization process is observed. This may be due to the fact that on increasing the catalyst dosage the number of active surface area increases for the dye molecules to get adsorbed ${ }^{31}$ and by adding excess amount of catalyst dosage, turbidity in the dye solution gets increased which in turn decreases the sunlight penetration as a result of which there is a decrease in the dye decolourization process.

\section{Effect of catalyst concentration}

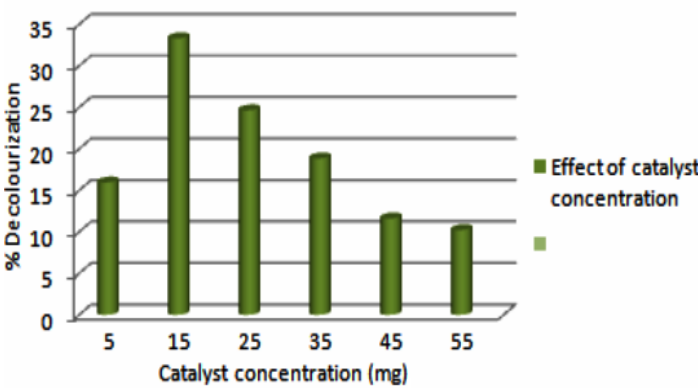

Fig. 9. $1.13 \times 10^{-5} \mathrm{~mol} / \mathrm{L}$ of acid green 1 dye solution, $\mathrm{BiOCl}$ catalyst dosage varied from $5 \mathrm{mg}$ to $55 \mathrm{mg}, \mathrm{pH}=5$, air flow rate $=2.5 \mathrm{~L} / \mathrm{min}$ under sunlight

Effect of initial dye concentration

The initial dye concentration of the acid green 1 dye is varied in the range $1.13 \times 10^{-5} \mathrm{~mol} / \mathrm{L}$ to $5.69 \times 10^{-5} \mathrm{~mol} / \mathrm{L}$ to find out the maximum dye concentration that can be decolourized with bismuth oxychloride photocatalyst $(15 \mathrm{mg} / 50 \mathrm{~mL}$ of dye solution) at optimized $\mathrm{pH}$ level 5 . The maximum decolourization of $A G 1$ dye is observed at a concentration of $2.27 \times 10^{-5} \mathrm{~mol} / \mathrm{L}$ which is shown in Fig. 10. The experimental results shows that beyond the concentration level of $2.27 \times 10^{-5} \mathrm{~mol} / \mathrm{L}$ there is a decrease in the dye decolourization process, this may be due to the fact that at higher dye concentration levels the number of active sites of the bismuth oxychloride photocatalyst available for the dye molecules is very less and hence the probability of the dye molecule to react with the hydroxyl ions is less which shows a retardation in the dye decolourization process ${ }^{32}$.

\section{Effect of Initial Dye Concentration}

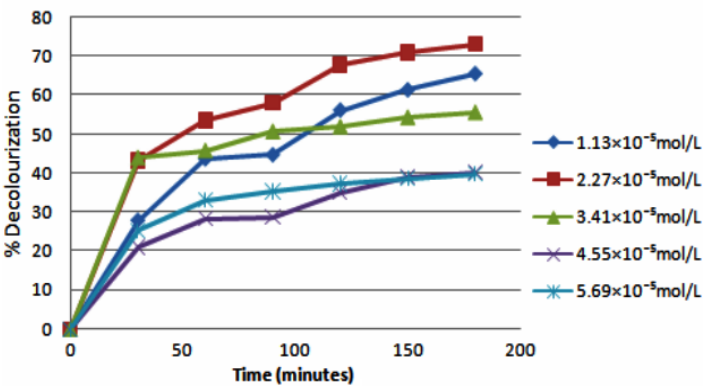

Fig. 10. $15 \mathrm{mg}$ of $\mathrm{BiOCl}$ catalyst, $\mathrm{pH}=5$, initial acid green 1 dye concentration varied from $1.13 \times 10^{-5} \mathrm{~mol} / \mathrm{L}$ to $5.69 \times 10^{-5}$ $\mathrm{mol} / \mathrm{L}$, air flow rate $=2.5 \mathrm{~L} / \mathrm{min}$ under sunlight

Effect of Different weight percent of AIF onto BiOCI photocatalyst

The photocatalytic response of both doped and undoped bismuth oxychloride photocatalyst is studied by doping different weight percent $(0.5$, $1,2,3$ and $4 w t \%)$ of aluminium fluoride which is shown in Fig. 11. The maximum dye decolourization is observed for $3 \mathrm{wt} \%$ of aluminium fluoride doped bismuth oxychloride photocatalyst within 90 min whereas the bare $\mathrm{BiOCl}$ photocatalyst degraded AG1 dye only at 180 min under similar experimental conditions and under dark condition in the absence of the sunlight only $18 \%$ of the dye got decolourized this may be due to the adsorption of the AG1 dye onto the photocatalyst surface. The faster degradation of AG1 dye with AIF-BiOCI photocatalyst may be attributed to the decrease in size of the catalyst with the surface area. Greater 
the surface-active sites available, greater will be the photocatalytic activity. A second factor responsible for the increase in photocatalytic degradation is the decrease in the band gap energy values. Generally, in a semiconductor the decrease in the band gap values causes generation of electrons and holes more quickly which further reacts with the hydroxyl radicals to degrade the dye molecules ${ }^{33}$.

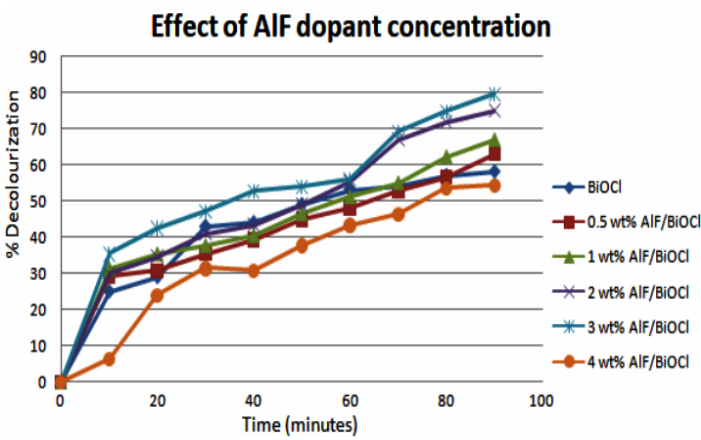

Fig. 11. shows the variation for different weight percent of AIF dopant concentration onto $\mathrm{BiOCl}$ catalyst for the photocatalytic decolourization of Acid green 1 dye

\section{Kinetic studies}

Langmuir-Hinshelwood ( $\mathrm{L}-\mathrm{H})$ kinetic model is used here to study the kinetics of doped and undoped heterogeneous semiconductor photocatalyst. This ( $\mathrm{L}-\mathrm{H})$ kinetic model has been widely used by several authors to find out the order of the reaction in heterogeneous semiconductor photocatalysis ${ }^{34-37}$. The kinetic studies carried out for the photocatalytic degradation of AG1 dye follows pseudo first order kinetics according to the equation.

$\ln \left[\mathrm{C}_{0}\right] /[\mathrm{C}]=\mathrm{kt}$

Where $\mathrm{k}$ is the pseudo-first-order rate constant $\left(\mathrm{min}^{-1}\right), \mathrm{C}_{0}$ is the concentration of dyes $\left(\mathrm{g} \mathrm{L}^{-1}\right)$ at $\mathrm{t}=0, \mathrm{C}$ is the concentration of dyes at reaction time $t$ (minute). The linear fit between In $\left[\mathrm{C}_{0} / \mathrm{C}\right]$ and irradiation time 't' for bismuth oxychloride and Aluminium fluoride $(0.5,1,2$ and $3 \mathrm{wt} \%$ ) doped bismuth oxychloride photocatalyst is shown in Fig. 12. The calculated average $\mathrm{R}^{2}$ value for the bare bismuth oxychloride photocatalyst is 0.9514 and for different weight percent of AIF-BiOCl were found to be 0.9196, 0.9629 and 0.9095 respectively.

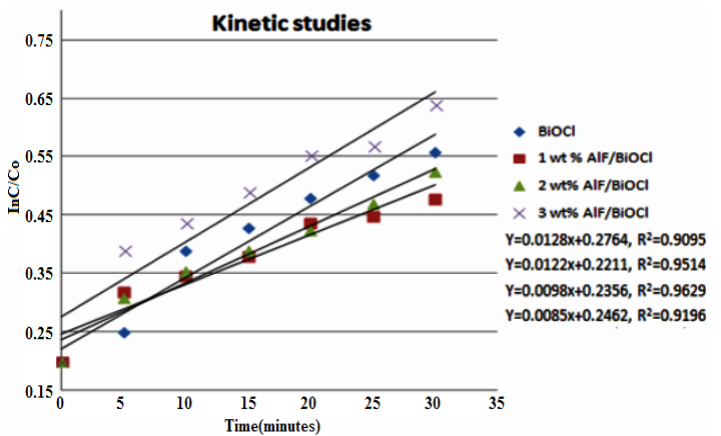

Fig.12. shows the pseudo-first order kinetic plot for the photocatalytic decolourization of Acid green 1 dye using different weight percent $(0-3 \%)$ of Aluminium fluoride doped Bismuth oxychloride catalyst

\section{CONCLUSION}

Aluminium fluoride doped bismuth oxychloride and bare bismuth oxychloride photocatalyst is prepared via simple chemical precipitation technique. The optical and morphological characteristics of the synthesized $\mathrm{BiOCl}$ and $\mathrm{AIF}-\mathrm{BiOCl}$ are studied and compared with the help of spectroscopy techniques such as XRD, FE-SEM, EDAX, FTIR, UV-DRS and BET surface area studies. The crystalline nature and hexagonal wurtzite structure of the synthesized $\mathrm{BiOCl}$ and AIF-BiOCl photomaterial is confirmed from the $X$-ray diffraction studies. The SEM images showed that the synthesized photomaterial possessed a flake-like structure and the major elements such as bismuth, oxygen, aluminium and fluorine in the synthesized photomaterial is confirmed from the EDAX data. The FTIR studies confirmed the metal-oxide bond formation and a decrease in the band gap and surface area of the AIF-BiOCl catalyst compared to that of the bare $\mathrm{BiOCl}$ photocatalyst is studied from the UV-DRS and BET surface area analysis. Further the photocatalytic activity carried out for the acid green 1 dye showed that AIF doped bismuth oxychloride photocatalyst degraded the dye within 90 min under sunlight radiation at optimized conditions whereas the bare bismuth oxychloride photocatalyst took more under similar optimized conditions. The photocatalytic reaction followed pseudo-first order kinetics according to LangmuirHinshelwood kinetic model. Thus, on concluding, AIF-BiOCl photocatalyst coupled with air oxidation under sunlight has proved to be an efficient photocatalyst for the degradation of the acid green 1 dye in aqueous solution. 


\section{ACKNOWLEDGEMENT}

The authors sincerely thank Dr. S. Thennarasu, Sr. Principal Scientist, Department of Organic and Bio-Organic Chemistry, Central Leather Research Institute, Chennai, for his valuable suggestions given for the successful completion of the work. We also thank $P G$ and Research
Department of Chemistry, Holy Cross College (Autonomous), Tiruchirappalli, for providing the necessary laboratory facilities.

\section{Conflict of Interest}

The authors declare that there is no conflict of interest.

\section{REFERENCES}

1. Brit., Synthetic Dyes: A look at Environmental \& Human Risks., 2008.

2. Matilainen, A.; Vepsäläinen, M.; Sillanpää, M., Natural Organic Matter Removal by Coagulation during Drinking Water Treatment: A Review. Advances in Colloid and Interface Science., 2010, 159(2), 189-97.

3. Liu, Y.; Zeng, G.; Tang, T., Highly effective adsorption of cationic and anionic dyes on magnetic $\mathrm{Fe} / \mathrm{Ni}$ nanoparticles doped bimodal mesoporous carbon, Journal of Colloid and Interface Science., 2015, 448, 451-549.

4. Khulbe, K.C.; Matsuura, T., Removal of heavy metals and pollutants by membrane adsorption techniques, Applied Water Science., 2018, 8,19.

5. Laisheng, Li.; Zhu, W.; Zhang, P.; Lu, P., UV/O3-BAC process for removing organic pollutants in secondary effluents, Desalination., 2017, 1-3, 114-124.

6. Song, L.; Pang, Y.; Zheng, Y.; Ge, L., Hydrothermal synthesis of novel g-C3N4/BiOCl heterostructure nanodiscs for efficient visible light photodegradation of Rhodamine B, Appl. Phys. A: Mater. Sci. Process., 2017, 123, 500.

7. Pu, X.; Zhang, D.; Gao, Y.; Shao, X.; Ding, G.; Li, S.; Zhao, S., One-pot microwave-assisted combustion synthesis of grapheme oxide- $\mathrm{TiO}_{2}$ hybrids for photodegradation of methyl orange, J. Alloys Compd., 2013, 551, 382-388.

8. Gao, X.; Zhang, X.; Wang, Y.; Peng, S.; Yue, B.; Fan, C., Rapid synthesis of hierarchical $\mathrm{BiOCl}$ microspheres for efficient photocatalytic degradation of carbamazepine under simulated solar irradiation, Chem. Eng. J., 2015, 263, 419-426.

9. Zhang, Y.; Zhang, Q.; Shi, Q.; Cai, Z.; Yang, Z., Acid-treated g-C3N4 with improved photocatalytic performance in the reduction of aqueous $\mathrm{Cr}(\mathrm{VI})$ under visible-light, Sep. Purif. Technol., 2015, 142, 251-257.

10. Yan, S.C.;Li,Z.S.;Zou,Z.G., Photodegradation of rhodamine $B$ and methyl orange over boron-doped g-C3N4 under visible light irradiation, Langmuir., 2010, 26, 3894-3901.

11. Seddigi, Z.S.; Gondal, M.A.; Baig, U.; Ahmed, S.A.; Abdulaziz, M.A.; Danish, E.Y., Facile synthesis of light harvesting semiconductor bismuth oxychloride nano photo-catalysts for efficient removal of hazardous organic pollutants, PLOS ONE., 2017, 12(2), e0172218.

12. Shen, K.; Gondal, M.A.; Al-Saadi, A.A.; Liye, L.; Chang, X.; Xu, Q., Visible light induced photodegaradtion of Rhodamine dyes over $\mathrm{BiOCl}$ and the vital importance of frontier orbital energy of the dye molecules in the reaction kinetics, Res. Chem. Intermed., 2015, 41, 2753-2766.

13. Kang, S.; Pawar, R.C.; Pyo, Y.; Khare, V.; Lee, C.S., Size-controlled BiOCl \pm RGO composites having enhanced photodegradative properties, J. Exp. Nanosci., 2016, 11, 259-275.

14. Li, K.; Liang, Y.; Yang, J.; Gao, Q.; Zhu, Y.; Liu, S.; Xu, R.; Wu, X., Controllable synthesis of 001 facet dependent four square $\mathrm{BiOCl}$ nanosheets: a high efficiency photocatalyst for degradation of methyl orange, J. Alloys. Compd., 2017, 695, 238-249.

15. Wen.; Ren, W. L.; Peng, F., Recent advances of bismuth oxychloride photocatalytic material: Property, preparation and performance enhancement, Journal of Electronic Science and Technology, 2020, 18(2), 100020.

16. Liu, X.; Su, Y.; Zhao, Q.; Du, C.; Liu, Z., Constructing $\mathrm{Bi}_{24} \mathrm{O}_{31} \mathrm{Cl}_{10} / \mathrm{BiOCl}$ heterojunction via a simple thermal annealing route for achieving enhanced photocatalytic activity and selectivity, Sci. Rep. Sci., 2016.

17. Zhao, H.; Tian, F.; Wang, F.; Chen, R., A Review on Bismuth-Related Nanomaterials for Photocatalysis, Reviews in Advanced Sciences and Engineering., 2014, 3, 1-25.

18. Raue.; Roderich.; Corbett.; John F., Nitro and Nitroso Dyes, Ullmann's Encyclopedia of Industrial Chemistry., 2000. 
19. Horobin, R.W.; Kiernan, J.A., Conn's Biological Stains: A Handbook of Dyes, Stains and Fluorochromes for Use in Biology and Medicine, BIOS Scientific. Publ., 2002, 101, 102.

20. Sharma, I.D.; Tripathi, G.K.; Sharma, V.K.; Tripathi, S.N.; Kurchania, R.; Kant, C.; Sharma, A.K.; Saini, K.K., One-pot synthesis of three bismuth oxyhalides $(\mathrm{BiOCl}, \mathrm{BiOBr}$, $\mathrm{BiOl})$ and their photocatalytic properties in three different exposure conditions, Cogent Chemistry., 2015, 1, 1076371.

21. Ascencio Aguirre, F.M.; Bazan Diaz, L.; Mendoza Cruz, R.; Vazquez, M.S.; Encinia, O.O.; Rodriguez, A.G.; Becerra, R.H., Chemical synthesis and characterization of bismuth oxychloride $\mathrm{BiOCl}$ nanoparticles, Appl. Phys. A., 2017, 123, 155.

22. Sharma, K.; Dutta, V.; Sharma, S.; Raizada, P.; Hosseini Bandegharaei A.; Thakur, P.; Singh, P., Recent advances in enhanced photocatalytic activity of bismuth oxyhalides for efficient photocatalysis of organic pollutants in water: A review, Journal of Industrial and Engineering Chemistry., 2019.

23. Xie, T.; Xu, L.; Liu, C.; Yang, J.; Wang, M., Magnetic composite BiOCl-SrFe ${ }_{12} \mathrm{O}_{19}$ : a novel p-n type heterojunction with enhanced photocatalytic activity, Dalton Trans., 2014, 43, 2211-2220.

24. Fruth, V.; Popa, M.; Berger, D.; Ionica, C.M.; Jitianu, M., Phase investigation in the antimony doped $\mathrm{Bi}_{2} \mathrm{O}_{3}$ system, J. Eur. Ceram. Soc., 2004, 24, 1295-1299.

25. Song, J.; Mao, C.; Niu, H.; Shen, Y.; Zhang, S., Hierarchical structured bismuth oxychlorides: self-assembly from nanoplates to nanoflowers via a solvothermal route and their photocatalytic properties, Cryst. Eng. Comm., 2010, 12, 3875-3881.

26. Tian, F.; Xiong, J.;Zhao, H.; Liu, Y.; Xiao, S.; Chen, R., Mannitol-assisted solvothermal synthesis of $\mathrm{BiOCl}$ hierarchical nanostructures and their mixed organic dye adsorption capacities, Cryst. Eng. Comm., 2014, 16, 4298-4305.

27. Wang, X.; Bi, W.; Zhai, P.; Wang, X.; Li, H.; Mailhot, G.; Dong, W., Adsorption and photocatalytic degradation of pharmaceuticals by BiOClxly Nanospheres in aqueous solution, Appl.Surf. Sci., 2016, 360, 240-251.

28. Di, J.; Xia, J.; Ji, M.; Wang, B.; Yin, S.; Zhang, Q.; Chen, Z.; Li, H., Carbon quantum dots modified $\mathrm{BiOCl}$ ultrathin nanosheets with enhanced molecular oxygen activation ability for broad spectrum photocatalytic properties and mechanism insight, ACS Appl. Mater. Interfaces., 2015, 7, 20111-20123.

29. Qiao, R.; Mao, M.; Hu, E.; Zhong, Y.; Ning, J.; Hu, Y., Facile formation of mesoporous BiVO4/Ag/AgCl heterostructured microsperes with enhanced visible-light photoactivity, Inorg. Chem., 2015, 54, 9033-9039.

30. Rashid, J.; Karim, S.; Kumar, R.; Barakat, M.A.; Akram, B.; Hussain, N.; Bin H.B.; Xu, M., A facile synthesis of bismuth oxychloride graphene oxide composite for visible light photocatalysis of aqueous diclofenac sodium, Scientific Reports., 2020, 10, 14191.

31. Grilla, E.; Kagialari, M.N.; Petala, A.; Frontistis, Z.; Mantzavinos, D.; Photocatalytic Degradation of Valsartan by $\mathrm{MoS}_{2} / \mathrm{BiOCl}$ Heterojunctions, Catalysts., 2021, 11, 650.

32. Seddigil, Z.S.; Gondal, M.A.; Baig, U.; Ahmed, S.A.; Abdulaziz1, M.A., Danish, E.Y.; Khaled, M.M.; Lais, A., Facile synthesis of light harvesting semiconductor bismuth oxychloride nano photo-catalysts for efficient removal of hazardous organic pollutants, PLOS ONE., 2017.

33. Li, H.; Li, J.; Zhihui, Ai.; Jia, F.; Zhang, L., Oxygen Vacancy-Mediated Photocatalysis of BiOCl: Reactivity, Selectivity, and Perspectives, Angew. Chem. Int. Ed., 2018, 57, 122-138.

34. Tanwar, R.; Mandal, U.K., Photocatalytic

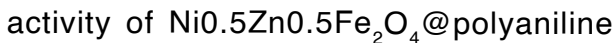
decorated $\mathrm{BiOCl}$ for azo dye degradation under visible light-integrated role and degradation kinetics interpretation, $R S C$ Adv., 2019, 9, 8977.

35. Ramachandran, S.; Sivasamy, A., Synthesis of nanocrystalline bismuth oxide and its visible photocatalytic activity in the degradation of an organic dye, Inorganic and Nano-Metal Chemistry., 2018.

36. Cui, P.; Wang, J.; Wang, Z.; Chen, J.; Xing, X.; Wang, L.; Yu, R., Bismuth oxychloride hollow microspheres with highvisible-light photocatalytic activity, Nano Research., 2015.

37. Cao, B.; Dong, P.; Cao, S.; Wang, Y., BiOCl/ $\mathrm{Ag}_{3} \mathrm{PO}_{4}$ Composites with Highly Enhanced Ultraviolet and Visible Light Photocatalytic Performances, J. Am. Ceram. Soc., 2013, 96(2), 544-548. 